\title{
An animal model to study iron availability from human diets
}

\author{
BY B. S. NARASINGA RAO, J. SIVA PRASAD \\ AND C. VIJAYA SARATHY \\ National Institute of Nutrition, Indian Council of Medical Research, \\ Hyderabad-500007, India
}

(Received 28 July 1976 - Accepted 6 September 1976)

\footnotetext{
I. The retention of ferric- and ferrous-iron was determined in guinea-pigs and monkeys using ${ }^{55} \mathrm{Fe}$ and ${ }^{59} \mathrm{Fe}$.

2. The bioavailability of $\mathrm{Fe}$ from two typical Indian diets based on rice and wheat was determined in humans and monkeys using a ${ }^{59} \mathrm{Fe}$ tracer and whole-body counting.

3. The retention ratio, ferric-Fe; ferrous-Fe was 0.90 in guinea-pigs and 0.33 in monkeys, indicating that monkeys absorb ferrous-Fe preferentially.

4. In monkeys retention of Fe from the test diets, as from ferrous ascorbate was lower than that in humans.

5. When food-Fe retention was expressed in relation to inorganic-Fe retention the value for retention ratio, food $\mathrm{Fe}$ : inorganic $\mathrm{Fe}$ in monkeys was similar to that in human subjects.

6 . The results indicate that the monkey can be used as a model to study $\mathrm{Fe}$ absorption from human diets.
}

Iron-deficiency anaemia is widespread in India despite an apparently satisfactory intake of dietary $\mathrm{Fe}$. Poor absorption of $\mathrm{Fe}$ from diets based predominantly on cereals can be one of the important causes of Fe deficiency. In any effort to identify the causes of anaemia and to develop methods for $\mathrm{Fe}$ prophylaxis, determination of $\mathrm{Fe}$ absorption from diets and from $\mathrm{Fe}$ sources used in prophylaxis is important. It has been realized in recent years that an isotopic method is the most reliable method of measuring food-Fe absorption, in humans. Routine testing of the availability of $\mathrm{Fe}$ in human subjects using radioactive $\mathrm{Fe}$ has limitations both from the point of view of obtaining willing volunteers and of radiological safety. In this context the development of an animal model for studying Fe absorption, the results of which are directly applicable to man, assumes considerable importance.

Rats and chicks have been widely used for determining the relative biological availability of dietary $\mathrm{Fe}$ (Fritz \& $\mathrm{Pla}$, 1972; Pla, Harrison \& Fritz, 1973). The applicability of information on $\mathrm{Fe}$ absorption obtained in the rat to human subjects has been questioned because of the observed differences in ferric-Fe absorption between the rat and man. While in man ferric-Fe is less well absorbed than ferrous-Fe (Brise \& Hallberg, 1962), these two forms of Fe are equally well absorbed by rats (Forth \& Rummel, I973), chicks (Pla \& Fritz, 1970) and dogs (Moore, Dubach, Minnich \& Roberts, 1944). There are also considerable differences in the effects of various dietary factors on $\mathrm{Fe}$ absorption between the rat and man (Cowan, Esfahani, Salji \& Azzam, I966). There is thus a need to develop an alternative animal model for studying the availability of dietary sources of $\mathrm{Fe}$ relevant to human nutrition. The possibility of using either the guinea-pig or the monkey for this purpose was 
therefore studied. These two species were chosen since both, like man, depend upon dietary sources of ascorbic acid to meet the requirement of this vitamin which plays an important role in the absorption and metabolism of $\mathrm{Fe}$.

\section{EXPERIMENTAL}

Two series of experiments were carried out. In the first series of experiments $\mathrm{Fe}$ retention from ferric- and ferrous-Fe was determined in guinea-pigs and monkeys. In the second series of experiments $\mathrm{Fe}$ retention from two typical diets was determined in humans and monkeys.

\section{Expt 1. Absorption of inorganic Fe}

Guinea-pigs. Thirteen adult female guinea-pigs with body-weights ranging from 500 to $65^{\circ} \mathrm{g}$ were used for the retention study. The animals were fasted for $2 \mathrm{~h}$ before dosing and on two consecutive days were given $\mathrm{r} \mathrm{ml}$ of a solution of either ferrous sulphate labelled with ${ }^{55} \mathrm{Fe}$ (Radiochemical Centre, Amersham, Bucks., UK) or ferric chloride labelled with ${ }^{59} \mathrm{Fe}$ (Bhabha Atomic Research Centre, Bombay, India). Both solutions contained $0.5 \mathrm{mg} \mathrm{Fe} / \mathrm{ml}$, and the solution was administered by stomach tube. ${ }^{59} \mathrm{Fe}$ retention was measured $12 \mathrm{~d}$ later by placing the animal in a plastic beaker on the stationary bed between the two crystals of the human wholebody counter (IAEA Model no. 3004/3; International Atomic Energy Agency, Vienna, Austria) as described by Narasinga Rao, Surendra Prasad \& Sharad Apte (1972). At the same time ${ }^{55} \mathrm{Fe}$ and ${ }^{59} \mathrm{Fe}$ activities in blood were determined by a modification of the procedure of Eakins \& Brown (1966), in which the re-precipitation of $\mathrm{Fe}(\mathrm{OH})_{3}$ was avoided and the final precipitation of the white complex of $\mathrm{Fe}$ was carried out directly in the liquid-scintillation counting-vial.

Monkeys. Twelve Rhesus monkeys, seven male and five female, with body-weights ranging from $\mathrm{I} \cdot 8$ to $2 \cdot 2 \mathrm{~kg}$, were used for the retention study. Monkeys were fasted overnight and given by stomach tube an accurately measured volume of freshly prepared ${ }^{55} \mathrm{FeSO}_{4}$ or ${ }^{59} \mathrm{FeCl}_{3}$ solution, providing $\mathrm{I} \mathrm{mg} \mathrm{Fe} / \mathrm{kg}$ body-weight on the two consecutive days. The animals were not given any food for the next $3 \mathrm{~h} .{ }^{59} \mathrm{Fe}$ retention was determined in a human whole-body counter as described by Narasinga Rao et al. (1972) immediately after the dose and I2 $\mathrm{d}$ later. The animals were anaesthetized with sodium Nembutal (Abbott Laboratories India Private Ltd, Bombay, India) before they were put in the whole-body counter. The animals were anaesthetized also after a dose of ${ }^{55} \mathrm{Fe}$ and the radioactivity determined thus was taken as the background level. At $12 \mathrm{~d}$ after the dose was given, blood samples were taken and ${ }^{55} \mathrm{Fe}$ and ${ }^{59} \mathrm{Fe}$ activities determined by liquid-scintillation counting by the method of Eakins \& Brown (rg66) using a liquid-scintillation spectrometer (Model no. 2211; Packard Instrument Company Inc., 2200 Warrenville Rd, Ill. $60515, \mathrm{USA})$.

In some animals, $\mathrm{Fe}$ retention from ferrous ascorbate at two levels of $\mathrm{Fe}, 3 \mathrm{mg} \mathrm{Fe}$ with $30 \mathrm{mg}$ ascorbic acid and $0.5 \mathrm{mg} \mathrm{Fe}$ with $5 \mathrm{mg}$ ascorbic acid, was also measured. 
Table I. Composition of rice-and wheat-based diets given as test meals for human volunteers and monkeys in Expt 2

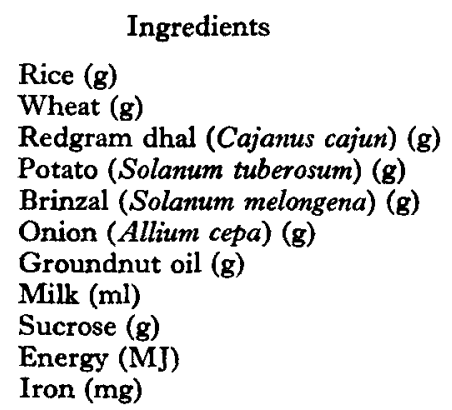

$\begin{array}{cc}\text { Rice-based diet } & \text { Wheat-based diet } \\ 200 & - \\ -70 & 70 \\ 75 & 50 \\ 50 & - \\ 25 & 15 \\ 10 & 20 \\ 160 & 40 \\ - & 20 \\ 4.88 & 2.51 \\ 9.6 & 5.2\end{array}$

\section{Expt 2. Absorption of Fe from the whole diet}

This study was carried out in humans and monkeys. Fe absorption from typical Indian diets based on rice and wheat was determined using an extrinsic label. The composition of the meals is given in Table $I$. Test meals based on the quantities given in Table $\mathrm{I}$ were given to each volunteer. Cooked diets were homogenized and made up to $2000 \mathrm{ml}$ with water and $100 \mathrm{ml}$ portions were given to each monkey.

Humans. Twenty-nine apparently healthy male laboratory workers were the subjects for the study. All subjects used for radioactive studies were volunteers who gave informed consent. Their ages ranged between 25 and 40 years and they had a haematological status similar to that of subjects studied previously (Narasinga Rao et al. 1972). The test meal containing a tracer dose of ${ }^{59} \mathrm{FeCl}_{3}\left(5 \mu \mathrm{Ci}, 0^{\circ} \times \mathrm{mg} \mathrm{Fe}\right)$ was fed to the subjects after an overnight fast. Fe retention was determined by whole-body counting, $12 \mathrm{~d}$ after the dose, as described previously (Narasinga Rao et al. I972). Standard Fe retention with $\left[{ }^{59} \mathrm{Fe}\right]$ ferrous ascorbate $(3 \mathrm{mg} \mathrm{Fe}$ and $30 \mathrm{mg}$ ascorbic acid) was also determined in all the subjects $12 \mathrm{~d}$ after one of the diets was tested.

Monkeys. Twelve male Rhesus monkeys with body-weights ranging from 2.0 to $2.5 \mathrm{~kg}$ were used for the retention study. The test meal was prepared in the same way as for human subjects, and then homogenized. The homogenized diet containing a tracer dose of ${ }^{59} \mathrm{FeCl}_{3}(10 \mu \mathrm{g} \mathrm{Fe} / \mu \mathrm{Ci})$ was given to monkeys by stomach tube after an overnight fast. Each monkey received $5 \mu \mathrm{Ci}{ }^{59} \mathrm{Fe}$. The amount of homogenized meal given corresponded to $(/ \mathrm{kg}) 100.50 \mathrm{~J}$ and $0.19 \mathrm{mg} F$ for the rice-based diet and $50.25 \mathrm{~J}$ and $0.10 \mathrm{mg} \mathrm{Fe}$ for the wheat-based diet; these levels were the same as those given to human subjects. Fe retention was determined as described previously. In each monkey, Fe retention was also measured with [ $\left.{ }^{59} \mathrm{Fe}\right]-$ ferrous ascorbate ( $3 \mathrm{mg} \mathrm{Fe}$ and $30 \mathrm{mg}$ ascorbic acid) I2 $\mathrm{d}$ after one of the diets was tested.

The technique of whole-body counting of ${ }^{59} \mathrm{Fe}$ radioactivity was essentially similar to that described for human subjects (Narasinga Rao et al. 1972 ). ${ }^{55} \mathrm{Fe}$ and ${ }^{59} \mathrm{Fe}$ activities in blood were determined by liquid-scintillation counting using a modification of the procedure of Eakins \& Brown (1966), as described previously. 
Table 2. Expt 1. Retention of ferrous- and ferric-iron (\% administered dose) in guineapigs and monkeys given test solutions of ${ }^{55} \mathrm{FeSO}_{4}$ and ${ }^{59} \mathrm{FeCl}_{3}{ }^{*}$ by stomach tube

\begin{tabular}{|c|c|c|c|c|c|c|c|c|}
\hline & $(\mathrm{M}$ & $n$ values & th their & standa & errors) & & & \\
\hline & \multirow{2}{*}{$\begin{array}{l}\text { No. of } \\
\text { subjects }\end{array}$} & \multirow{2}{*}{$\begin{array}{l}\text { Haemo- } \\
\text { globin } \\
(\mathrm{g} / \mathrm{l}) \\
\text { (range) }\end{array}$} & \multicolumn{2}{|c|}{$\begin{array}{l}\text { Ferric-Fe } \\
\text { retention }\end{array}$} & \multicolumn{2}{|c|}{$\begin{array}{l}\text { Ferrous-Fe } \\
\text { retention }\end{array}$} & \multicolumn{2}{|c|}{$\begin{array}{c}\text { Ferric-Fe }: F e r- \\
\text { rous-Fe }\end{array}$} \\
\hline & & & Mean & SE & Mean & SE & Mean & $\mathrm{SE}$ \\
\hline Guinea-pigs & I3 & $104-147$ & 7.0 & 0.73 & $8 \cdot 6$ & $I \cdot 12$ & 0.90 & 0.075 \\
\hline Monkeys & 12 & $119-149$ & $3 \cdot 8$ & 0.25 & I 3.8 & $r \cdot 86$ & 0.33 & 0.047 \\
\hline Human male $(\dagger)$ & I I & $146-180$ & $8 \cdot 3$ & $2 \cdot 10$ & $30 \cdot 2$ & 3.04 & 0.35 & 0.097 \\
\hline
\end{tabular}

\section{RESULTS}

The results of the retention studies with ferric and ferrous salts in guinea-pigs and monkeys are presented in Table 2.

The retention of $\mathrm{Fe}$ from $\mathrm{FeCl}_{3}$ in guinea-pigs ranged between 3.7 and $10.5 \%$ administered dose. The retention of $\mathrm{Fe}$ from $\mathrm{FeCl}_{3}$ in monkeys ranged between $2 \cdot 9$ and $5.3 \%$ administered dose.

Retention of $\mathrm{Fe}$ in monkeys from ferrous ascorbate at two different levels of Fe $(3.0 \mathrm{mg}$ and $0.5 \mathrm{mg}$ ) showed that retention (\% administered dose) was similar at these two levels. The mean $( \pm \mathrm{SE})$ retention of $\mathrm{Fe}$ from ferrous ascorbate $(\%$ administered dose) at the $3.0 \mathrm{mg}$ Fe level was $12 \cdot 2 \pm 1 \cdot 84$ in six males and $10 \cdot 6 \pm 1 \cdot 64$ in six females. The retention of Fe of a test dose of $0.5 \mathrm{mg}$ Fe from ferrous ascorbate was $9.9 \pm \mathrm{I} \cdot 7 \mathrm{O}$ (SE) \% administered dose in male monkeys. The difference in the retention at $3.0 \mathrm{mg}$ and $0.5 \mathrm{mg}$ Fe levels was not statistically significant. This finding suggests that food-Fe retention where $\mathrm{Fe}$ intake is about $0.5 \mathrm{mg}$ could be related to standard Fe retention with a dose of ferrous ascorbate containing $3 \mathrm{mg} \mathrm{Fe}$.

Results of studies on Fe retention from rice- and wheat-based meals are presented in Table 3. The Fe retention in human subjects ranged between 1.5 and $18.1 \%$ administered dose from the rice-based meal and between 0.7 and $3.4 \%$ administered dose from the wheat-based meal. Fe retention for a standard dose of ferrous ascorbate ranged from $\mathrm{II} \cdot 3$ to $48 \cdot 8 \%$ administered dose in human subjects. The retention ratio, food $\mathrm{Fe}$ :ascorbate $\mathrm{Fe}$ ranged between 0.12 and 0.60 with rice-based meal and from 0.026 to 0.087 with wheat-based meal. Ascorbate-Fe retention in monkeys was $12.2 \%$ administered dose and was lower than in human subjects. In monkeys $\mathrm{Fe}$ retention from the rice-based meal ranged between 1.3 and $3.9 \%$ administered dose and retention ratio, food $\mathrm{Fe}$ :ascorbate $\mathrm{Fe}$ ranged between 0.10 and 0.24 . The Fe retention from wheat-based meal ranged between 0.64 and $\mathrm{I} .40 \%$ administered dose. The retention ratio, food $\mathrm{Fe}$ :ascorbate $\mathrm{Fe}$ ranged from 0.05 to 0.19 . As with ascorbate-Fe retention, food-Fe retention was also lower in monkeys as compared to humans for both diets. However, when food-Fe absorption was expressed relative to ascorbate-Fe retention, the value for the retention ratio in monkeys was similar to that observed in human subjects for both diets. 
Table 3. Expt 2. Food-iron and ascorbate-Fe retention (\% administered dose) in monkeys and in human volunteers given test meals* based on rice or wheat and containing a tracer dose of ${ }^{59} \mathrm{FeCl}_{3}$, or test solutions of $\left[{ }^{59} \mathrm{Fe}\right]$ ferrous ascorbate $\dagger$

(Mean values with their standard errors)

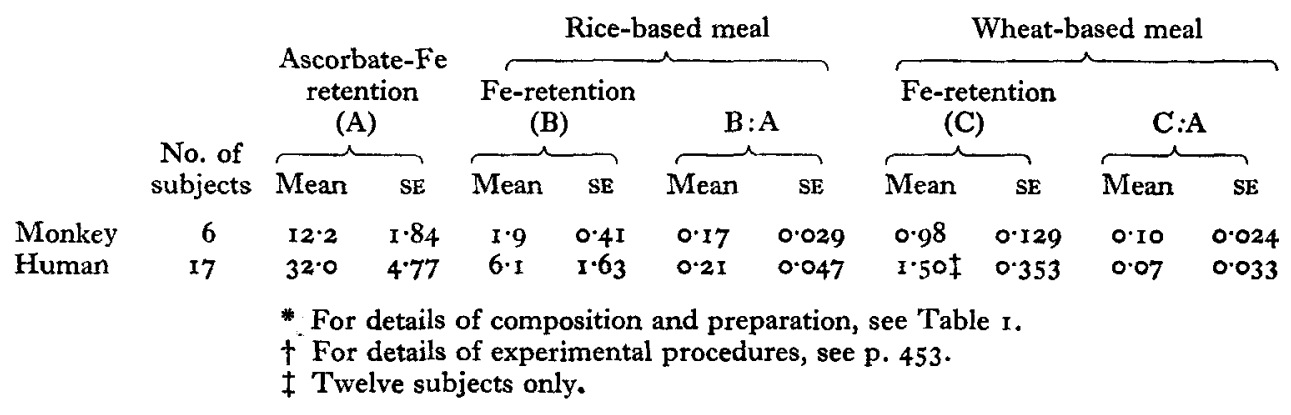

\section{DISCUSSION}

There is the need to have an animal model for measuring Fe absorption from foods and other Fe sources intended for human use. Such a model would allow the testing of a large number of foods and Fe sources rapidly at relatively low cost. Rats and chicks have been used to test $\mathrm{Fe}$ sources for their bioavailability (Fritz \& Pla, 1972; Pla et al. 1973). As mentioned previously these species do not distinguish between ferric and ferrous sources of $\mathrm{Fe}$ which are differently absorbed in human subjects. Attempts have been made to compare relative availability of $\mathrm{Fe}$ sources in rats and humans ( $\mathrm{Pla}$ et al. 1973). In this study, however, Fe availability in humans was assessed on the basis of plasma Fe levels after oral ingestion of the Fe source, while in rats the assessment was based on haemoglobin regeneration. The value of such a comparison is difficult to assess.

In the present study an attempt was first made to identify a species which differentiates between ferrous- and ferric-Fe during absorption in the same way as human subjects. Of the two species studied, the monkey was found to absorb ferric-Fe less efficiently than ferrous-Fe. The retention ratio, ferric-Fe:ferrous-Fe was 0.3 in the monkey, a value comparable to that found in man (Brise \& Hallberg, 1962; Narasinga Rao et al. 1972). The guinea-pig was found to be unable to differentiate between absorption of ferrous- and ferric-Fe. Rats (Forth \& Rummel, 1973), chicks (Pla \& Fritz, 1970) and dogs (Moore et al. r944) have been shown previously to absorb ferric- and ferrous-Fe equally well.

The absorption of $\mathrm{Fe}$ from two habitual Indian diets based on either rice or wheat was determined and the values compared with those obtained in humans given the same diets. The absolute values for retention of $\mathrm{Fe}$ from these diets in monkeys were lower than the values obtained in human subjects. It is known that food-Fe absorption is related to inorganic-Fe absorption (Cook, Layrisse \& Finch, I969). Thus, for comparative purposes, food-Fe absorption is best expressed relative to absorption of Fe from ferrous ascorbate (Layrisse, Cook, Martinez, Roche, Kuhn, Walker \& Finch, 1969). Inorganic-Fe absorption in monkeys was lower than in human subjects. 


\section{B. S. Narasinga Rao, J. Siva Prasad and C. Vijaya Sarathy i977}

However, the values for the retention ratio, food $\mathrm{Fe}$ :inorganic $\mathrm{Fe}$ for these two diets in monkeys was similar to those obtained for human subjects.

These results indicate that the monkey can be used as a model to study $\mathrm{Fe}$ absorption from human diets. The values obtained with monkeys can be applied to human subjects after correcting for differences in inorganic-Fe absorption between the two species.

The authors are grateful to Dr S. G. Srikantia, Director National Institute of Nutrition, Hyderabad-500007, for his keen interest, encouragement and helpful suggestions during this study. This work was supported in part by research grant (673/R4/RB) from International Atomic Energy Agency, Vienna, Austria.

\section{REFERENCES}

Brise, H. \& Hallberg, L. (1962). Acta med. scand. 171, Suppl, 376, 7.

Cook, J. D., Layrisse, M. \& Finch, C. A. (1969). Blood 33, 421.

Cowan, J. W., Esfahani, M., Salji, J. P. \& Azzam, S. A. (1966). F. Nutr. 90, 423.

Eakins, J. D. \& Brown, D. A. (1966). Int. F. appl. Radiat. Isotopes 17, 391.

Forth, W. \& Rummel, W. (1973). Physiol. Rev. 53, 724.

Fritz, J. C. \& Pla, G. W. (1972). Э. Ass. analyt. Chem. 55, I 128.

Layrisse, M., Cook, J. D., Martinez, C., Roche, M., Kuhn, I. N., Walker, R. B. \& Finch, C. A. (1969). Blood 33, 430.

Moore, C. V., Dubach, R., Minnich, V. \& Roberts, H. K. (1944). Y. clin. Invest. 23, 755.

Narasinga Rao, B. S., Surendra Prasad \& Sharad Apte (1972). Br. F. Haemat. 22, 28 I.

Pla, G. W. \& Fritz, J. C. (1970). J. Ass. analyt. Chem. 53, 79r.

Pla, G. W., Harrison, B. N. \& Fritz, J. C. (1973). F. Ass, analyt. Chem. 56, I369. 